\section{Perspectivas de la Cartografía Social, experiencias entre extensión, investigación e intervención social}

\author{
Juan Manuel Diez Tetamanti \\ jmdiezte@gmail.com \\ Magali Elizabeth Chanampa \\ magalichanampa@gmail.com
}

\author{
Docentes investigadores de la \\ Universidad Nacional de la Patagonia \\ San Juan Bosco, Argentina. \\ Investigadores del Consejo \\ Latinoamericano de Ciencias Sociales \\ (CLACSO) y del Consejo Nacional de \\ Investigaciones Científicas y Técnicas \\ (CONICET), Argentina.
}

Integración de la docencia y la extensión /

Perspectivas

RECEPCIÓN: 24/06/16

ACEPTACIÓN FINAL: 05/10/16

\section{Resumen}

Concebimos a la Cartografía Social como un proceso productivo que implica una sucesión de eventos y fases en torno a la conjunción de representaciones colectivas y transformaciones a partir de la producción de nuevos sentidos espaciales. Nuestra experiencia nos ha demostrado nuevos espacios de producción y deconstrucción de lo que entendemos como mapa, texto, proyección, e ingresamos así en una necesaria interdisciplinariedad que nos permita abordar un texto cartográfico colectivo que deconstruye la noción de cartografía tradicional. Mediante un breve recorrido sobre este método y práctica, proponemos profundizar en los ejes que hacen a su aplicación. El principal objetivo teórico-metodológico del artículo es el aporte que podamos ofrecer a la investigación, extensión e intervención social, desde una perspectiva de comunión entre estos espacios de acción. En este sentido, consideramos la sección Intervenciones de la presente convocatoria, como un espacio acorde a los fines y contribuciones del siguiente artículo. Finalmente, cabe resaltar que a partir de la experiencia de ocho años de trabajo con Cartografía Social, en 2014 se creó la Cátedra Libre de Cartografía Social, en el seno de la Universidad Nacional de la Patagonia, a partir de la cual se han dictado múltiples cursos y talleres tanto en Argentina como en Brasil, Uruguay, Costa Rica y Mozambique.

\section{Resumo}

Entendemos a Cartografia Social como um processo produtivo que implica uma sucessão de eventos e fases em torno à conjunção de representações coletivas e transformações a partir da produção de novos sentidos espaciais. A nossa experiência tem nos demonstrado novos espaços de produção e de desconstrução do que entendemos como mapa, texto, projeção; dessa forma ingressamos numa necessária interdisciplinariedade, que nos permita abordar um texto cartográfico coletivo que desconstrói a noção de cartografia tradicional. A través de um breve percurso sobre este método e a prática, propomo-nos aprofundar nos eixos que fazem possível a sua aplicação. O principal objetivo teórico-metodológico do artigo é a contribuição que possamos oferecer à pesquisa, extensão e intervenção social, a partir de uma perspectiva da comunhão entre esses espaços de ação. Neste sentido, consideramos a seção de Intervenções da presente convocação, como o espaço adequado para tais fins e contribuições do artigo a seguir. Finalmente, é necessário salientar que a partir da experiência de oito anos de trabalho com Cartografia Social, em 2014 se criou a Cátedra Livre de Cartografia Social, no seio da Universidade Nacional de la Patagonia, que já tem ministrado múltiplos cursos e oficinas tanto na Argentina, quanto no Brasil, Uruguai, Costa Rica e Moçambique.

Palavras-chave

- Cartografia social

- Pesquisa

- Extensão

- Intervenção

- Método
Para citación de este artículo

Diez Tetamanti, J. M. y Chanampa, M. E. (2016).

Perspectivas de la Cartografía Social, experiencias entre extensión, investigación e intervención social. En Revista +E versión digital, (6), pp. 84-94. Santa Fe, Argentina: Ediciones UNL. 


\section{Introducción}

En los últimos seis años hemos estado trabajando en función de la conceptualización y metodología de Cartografía Social. El trabajo partió de una inicial curiosidad por la práctica de este método, que luego se fue complejizando. El interés se concentró en: explorar los modos de construir "otras cartografías", analizar los resultados de los talleres llevados a cabo y; generar nuevas conceptualizaciones que nos permitan hacer aportes a la geografía y otras disciplinas. Así, en 2012 publicamos nuestro primer libro: Cartografía Social, investigación e intervención desde las ciencias sociales (Diez Tetamanti y Escudero, 2012), que concentra el aporte de investigadores, docentes y estudiantes de Argentina y Brasil. Esta obra fue parte de una primera aproximación al tema que emergió desde la interacción entre la extensión y la investigación como práctica cotidiana. Luego de esta publicación continuamos escribiendo y ensayando con Cartografía Social, lo que nos llevó a dictar más de 40 talleres en Argentina y otros países, tanto en vinculación con universidades como con organismos de gobierno y organizaciones sociales.

En esta línea de trabajo, nos asombramos y entusiasmamos con el interés que convoca la práctica y reflexión sobre Cartografía Social en las ciencias sociales y, en particular, en Geografía. Advertimos que podríamos generar aportes de reflexión para la adquisición de instrumentos que permitan a la ciencia geográfica avanzar en nuevas propuestas y producciones, saltando del paradigma de la representación, para cultivar la producción de nuevos espacios y textos que dialoguen sobre los territorios producidos en las cartografías.

Nos preguntamos permanentemente si la Cartografía Social es un método, una propuesta conceptual, una herramienta o un simple modo de "hacer mapas". Además de los textos revisados en estos años relacionados con la Cartografía Social (Montoya, 2007; Mattos, Damas y Cavalli, 2014; Piza Cubides, 2009; Torres Ribeiro, 2009; García Barón, 2007; entre otros), nuestra experiencia nos ha demostrado nuevas formas de producción y deconstrucción de lo que entendemos como mapa, texto, proyección, e ingresamos así en una necesaria interdisciplinariedad que nos permita abordar un texto cartográfico colectivo, que deconstruye la noción de cartografía tradicional y la ubica en el centro a la producción, en un juego móvil y difuso, que al mismo tiempo encierra una inmensa riqueza a explorar. En esta línea, la Cartografía Social se abre paso entre una diversidad de métodos de investigación y extensión que ponen en práctica y prueba conceptos y marcos teóricos y que al mismo tiempo se ponen en juego comunitariamente en un proceso de intensa intertextualidad. Desde la definición de espacio hasta el análisis de los cuerpos, ingresan en el gran texto que compone el proceso productivo comunitario y participativo de Cartografía Social, tanto desde la investigación como desde la intervención en lo social, propulsado, en este caso aquí presentado, desde la extensión universitaria.

Al practicar Cartografía Social nos encontramos obrando sobre la base del método cartográfico ${ }^{1}$ de Deleuze y Guattari (1995), incursionamos en la teoría de la deriva de Debord (1958), nos perdemos y transitamos la experiencia nómada como punto de encuentro errante de Careri (2014), la cual no solo propiciará un acercamiento deconstruido y colectivizado a los famosos mapas mentales de Kevin Lynch (1986) sino que también nos aproximará al espacio como sujeto activo y vibrante, productor autónomo de afectos y de relaciones (Careri, 2014). Mientras compartimos, construimos conocimiento sobre el territorio experimentado, creamos permanentes líneas de fuga del paradigma de la
1) Desemaranhar as linhas de um dispositivo é, em cada caso, traçar um mapa, cartografar, percorrer terras desconhecidas, é o que Foucault chama de trabalho de terreno. É preciso instalarmo-nos sobre as próprias linhas, que não se contentam apenas em compor um dispositivo, mas atravessam-no, arrastam-no, de norte a sul, de leste a oeste ou em diagonal (Deleuze y Guattari 1995). 
representación, nos internarnos en un fantástico plano común que envuelve las singularidades y consensos de los cartógrafos sociales (Kastrup, 2014).

Podríamos definir a la Cartografía Social como un procedimiento que convoca a un proceso productivo, que implica una sucesión de eventos y fases reunidas en un hecho complejo. También podemos definirla como método, dada su estructura que permite un resultado. Al mismo tiempo difinirla como máquina deleuziana de producción generadora de mapas, representaciones colectivas y transformaciones a partir de la producción de nuevos sentidos espaciales (Debord y Wolman, 1956). Es decir, un método de proceso maquínico en el cual intervienen sí o sí más de dos sujetos, los cuales producen, a partir de la intertextualidad de experiencias y prácticas, sobre el mundo a representar y, al mismo tiempo: generan nuevos sentidos espaciales que incrementan el conocimiento de los partícipes sobre ese espacio y, en oportunidades, colaboran en el obrar sobre él.

Sobre esta perspectiva de Cartografía Social nos interesa abonar un terreno de obraje que permita la práctica intensiva de extensión e investigación a partir de la intervención social.

\section{De la representación a la producción}

Las representaciones del espacio enmarcadas como espacio subjetivo han pasado por numerosas discusiones. En la década de 1960, esta temática se popularizó en el marco de la "Geografía de la Percepción", asociada a la utilización de mapas mentales a través de la obra de Lynch. Esto desplegó, al interior de la Geografía, una interesante discusión sobre el espacio percibido y el espacio vivido. Para Vara:

"La objetividad del espacio suele identificarse con el espacio geográfico, el de la cartografía y el de los técnicos que trabajan sobre él. (...) Mientras que la base teórica de Geografía de la percepción se ha fundamentado en la existencia de dos espacios distinguibles: el espacio objetivo como realidad extramental y el espacio subjetivo o vivido". (2010:339)

Así, esa división es falsa ya que:

"El espacio, puesto que es siempre subjetivo, se estudia a través de percepciones. Las técnicas no son métodos, sino las herramientas que nos permiten acceder, medir y evaluar las percepciones espaciales. Puesto que el espacio es una categoría sin sustancia, es decir, su sustancia es la relatividad (Bailly, 1981) los soportes en los que queda plasmada esa relatividad son tan importantes como el estudio del espacio mismo". (342)
La cartografía siempre forma parte de un discurso, de una administración del saber, una política del saber, y en muchos casos, como parte de su naturaleza, representa a instrumentos de dominación que responden a un saber y un poder determinado (Foucault, 1979). En la práctica de Cartografía Social se genera una red y circuitos de poderes superpuestos, de consensos y disensos que se plasman en el mapa-texto, lo que incluye en el producto intertextual, al cuerpo y las experiencias territoriales que son, en definitiva, la proyección cartográfica de la Cartografía Social. Desde ella se propone subvertir ciertos universalismos como el de la cartografía tradicional, propia del poder estratégico administrativo que tiende a separar y fragmentar, seleccionar y omitir, en un proceso altamente normado y controlado de modo estratégico en función a intereses e intencionalidades vinculados esencialmente a los sectores dominantes del saber tecnocartográfico, académico o militar. Al mismo tiempo, en Cartografía Social el énfasis del análisis y el resultado no está puesto en el "producto mapa" o en el "mapa como imagen", tal como plantean algunas perspectivas, como es el caso de Carla Lois (2009) en su trabajo denominado "Imagen cartográfica e imaginarios geográficos. Los lugares y las formas de los mapas en nuestra cultura visual", sino que la Cartografía Social prioriza en el proceso de producción del mapa que involucra un diálogo colectivo, debate, creación del mapa y presentación oral en donde a su vez confluye la subjetividad de cada uno de los sujetos implicados, elementos que resumen lo que denominamos intertextualidad del mapa. En este sentido, lo que vamos a mencionar como "mapa" no es de facto el mapa tradicional sino un compuesto complejo elaborado a partir del diálogo, la memoria, las representaciones subjetivas, el conocimiento y las singularidades constituyentes en "un plano común", donde el mapa como dibujo o producto es sólo una parte complementaria y no trasciende el proceso colectivo de construcción cartográfica.

Antes de continuar resulta necesario comentar brevemente el método cartográfico (al cual adherimos desde la práctica de Cartografía Social), propuesto inicialmente por Giles Deleuze (1998), en el que sujeto y objeto no están divorciados y la comunión de ambos se amalgama en el proceso de la experiencia compartida y móvil. Este proceso de la experiencia coloca tanto al investigador como al objeto de la investigación en un plano común en donde la experiencia es el proceso que los unifica en el diálogo e intercambio de información, por el cual ambos: sujeto investigador y sujeto investigado (tradicionalmente, objeto) comparten elementos de la experiencia. Un proceso de enriquecimiento sobre el conocimiento de la realidad experimentada a partir del diálogo de sujetos heterogéneos, que comparten sucesos comunes por medio de diferentes subjetividades (Kastrup, 2014). 


\section{podríamos definir a la Cartografía Social como un procedimiento que convoca a un proceso productivo, que implica una sucesión de eventos y fases reunidas en un hecho complejo}

La implicación del sujeto investigador con el investigado hace difusos los límites entre ambos. Ante esto, Kastrup menciona que el método cartográfico es siempre de investigación e intervención al mismo tiempo, ya que:

"No mantiene una relación de oposición entre investigador e investigado, tomados como realidades preestablecidas, y descoloca esa polarización para asegurar una correlación de coproducción y convergencia" (27).

Siguiendo en esta línea, lo que el método cartográfico procura es hablar en conjunto con la "experiencia de la realidad" y no "sobre la realidad", produciendo un evento de implicación entre el investigador y el investigado. Esa implicación garantiza un protagonismo del objeto tradicional, en tanto productor de conocimiento y cuestionador de los estándares de construcción de esa producción, dado que permanentemente deconstruye los estándares de la producción cartográfica y académica. Así se produce una doble función: por un lado, se generan datos que podrán sistematizarse (sobre el territorio experimentado) y, por otro lado, se genera un proceso de transformación de la experiencia del participante, en el que la experiencia del otro es indispensable para la creación de un producto colectivo (Kastrup, 2014). De este modo, se promueve el protagonismo de todos sus participantes en un plano productivo, que es siempre plano común. Lo común, así, trasciende a lo singular del sujeto porque lo pone en una misma posibilidad de registro a la experiencia con los otros al tiempo que incluye las singularidades de la experiencia, siempre singular y subjetiva, en tanto se consuma un evento creador (mapa) a partir de la intertextualidad de experiencias.

El método cartográfico, a partir de Passos, Kastrup y Escóssia (2010), genera una triple inclusión: una, porque coloca en un plano horizontal a diferentes singularidades y sujetos distintos que dialogan, crean interés en el tema abordado y producen un producto común. Otra, porque esta inclusión de los sujetos como partícipes de la investigación propicia un efecto crítico en los analizadores de la investigación, sobre sus propias prácticas y, finalmente, la investigación se hace efectiva al mismo tiempo que se genera una experiencia colectiva de intervención y diálogo que es siempre deconstructivo del carácter de la experiencia individual. En este contexto, cartografía es un término que hace referencia a la idea de mapa, desprovista de centro estático y en permanente deconstrucción, que procura visibilizar las intensidades y texturas, abre el registro al acompañamiento de las transformaciones que acontecen en el terreno experimentado e ingresa en espacio producido a partir del consenso dada su interrelación de textos producidos en el diálogo productivo.

Al respecto de la relación representación-producción en el terreno de la cartografía tradicional, Harley (1988) hace hincapié en el icono, signo convencional y arbitrario, el cual pocas veces es puesto en duda en el contexto del mapa. El signo es así, representación de la verdad que impone el mapa. Una verdad donde la economía de su utilización y los tamaños son arbitrariamente dispuestos por el sujeto cartógrafo y la institución que avala el mapa. Signo y verdad comulgados en mapa representan "lo que hay", "cómo es", casi sin debate ni retórica, reproduciendo las jerarquías sociales, políticas y económicas con autoridad sobre el territorio.

La reproducción y representación en serie y la homogeneización de objetos es de elemental necesidad en el mapa tradicional, de modo que éste pueda establecer comparaciones, diferencias y límites. Agamben (2011), en Kalumniator, hace un análisis del agrimensor de la novela El Castillo de Kafka. La necesidad de construir límites y líneas rectas que dividan se debate internamente en el agrimensor. El autor menciona que:

"Lo que le interesa al agrimensor, es el límite que divide y que une, lo que desea abolir, o mejor, hacer inoperante. Pues por donde pasa materialmente ese límite, nadie parece saber, tal vez él en la realidad no exista, pero pase, así como una puerta invisible, por dentro de todos los hombres". ${ }^{2}$ (57) 


\section{6}

el mapa social como proceso

deconstructivo trabaja en una doble

funcionalidad mimética y diegética

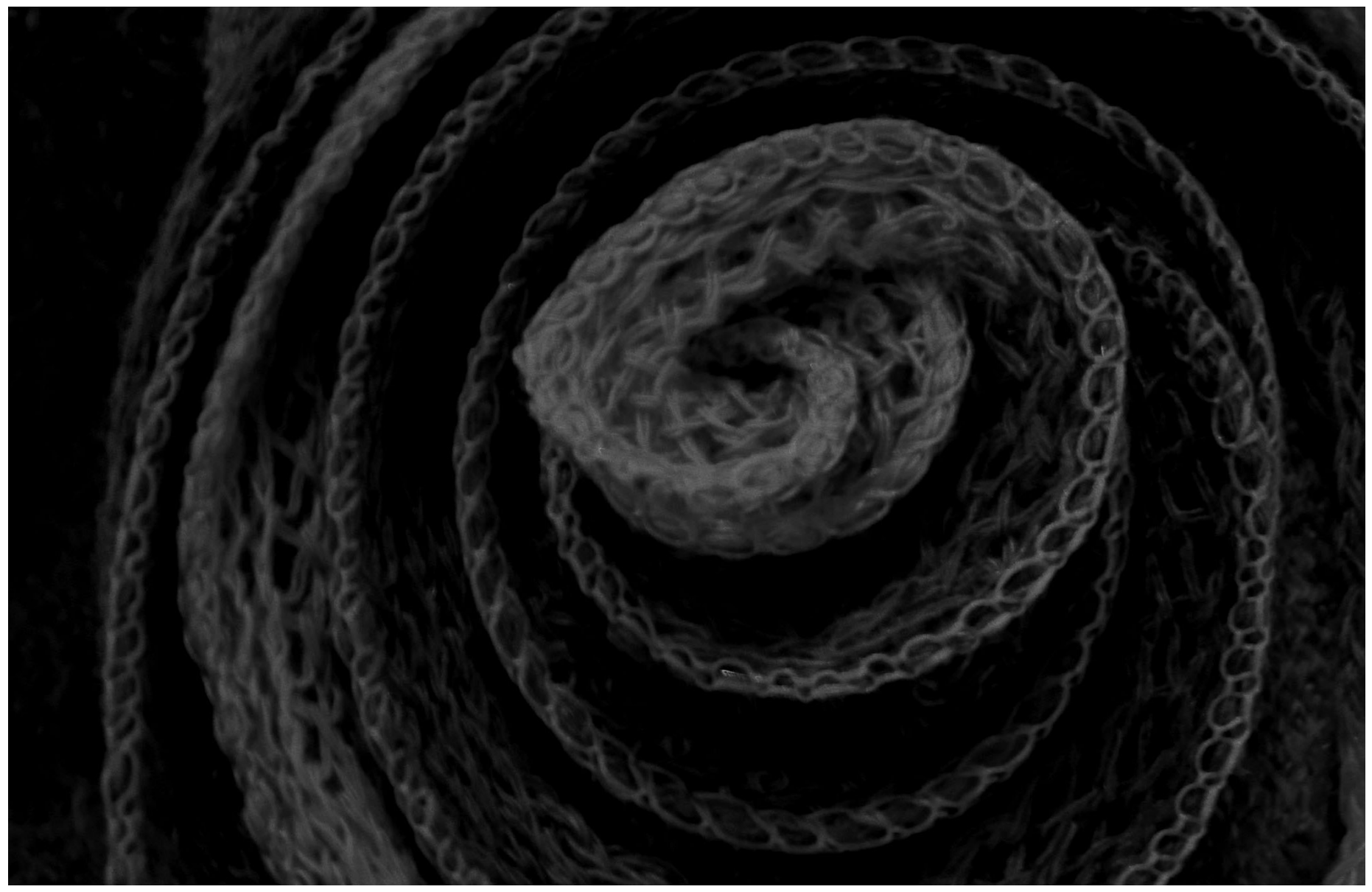

() Marcela Pinotti 
Son esos otros límites permitidos en el seno de la Cartografía Social, desde donde podemos empezar a producir nuevas realidades consensuadas. Nuevos límites no ortodoxos que nos permitan nuevas convenciones, verdades y realidades alternativas, con apertura a otras posibilidades y cambios en el mundo cotidiano. Así, la producción bajo proyecciones diseñadas por la propia textura social, el consenso y el disenso, la creación de otras convenciones, móviles o efímeras, abren paso a través de la práctica de Cartografía Social a un proceso de deconstrucción, para luego construir nuevos mapas lo cual implica, en palabras de Norris (1987, citado en Harley 1988):

"poner a funcionar una suerte de estrategia inversa buscando, precisamente, en todos esos detalles que se han descuidado y que siempre, y necesariamente, fueron pasados por alto por los intérpretes de una tendencia más ortodoxa. Es aquí, en los márgenes del texto, según los define un consenso fuertemente normativo, que la deconstrucción descubre el funcionamiento de esas mismas fuerzas, como desconcertante". (11)

El mapa social como proceso deconstructivo trabaja en una doble funcionalidad mimética y diegética. Mimética porque trae al plano de la obra colectiva (la hoja en blanco) y al espacio de las representaciones singulares de "mapa", los conocimientos preconcebidos y sobre la cartografía que intentarán reproducir calcográficamente el dibujo, a la vez que es diegética, ya que se genera una operación de intento de estructurar la realidad, que es también una construcción singular de los cartógrafos sociales. Esa producción de un espacio singular y reelaborado es lo que constituye a la práctica como diegética (Burch, 1987).

\section{Experiencia, método y comunión: extensión- investigación-intervención}

La fuerte perspectiva empírica y de extensión ${ }^{3}$ que tiene la génesis de la Cartografía Social en nuestro grupo de trabajo nos ha incentivado por un lado, a avanzar en una exploración conceptual que nos facilitó crear un dispositivo para la intervención ${ }^{4} \mathrm{y}$, por otro lado, a encontrar algunos puntos para su sistematización que conviertan al trabajo cotidiano de extensión, también en un corpus metodológico que se abra a objetivos de investigación.

En este camino, hemos trazado un dispositivo "no acabado" como parte de la batería metodológica que incluye a todo el proceso, desde el inicio de la planificación, hasta el final de la presentación de los mapas realizados. Nos aproximamos a este proceso en términos de Careri (2014), cuando se refiere a la metáfora de la deriva, como "proyecto indeterminado" en tanto instrumento para la construcción de una dirección y en sintonía con lo que nos acerca Agamben (2011) sobre dispositivo, que refiere a la disposición de una serie de prácticas y mecanismos, con el objetivo de hacer frente a una urgencia y de conseguir un efecto.

En los inicios de nuestras prácticas de Cartografía Social, nos valíamos de una serie de consignas abiertas y algunas guías para proponer un mapeo colectivo. A partir de la intervención en diversos talleres, el método se fue complejizando, tal como puede verse en (Diez Tetamanti y Escudero, 2012; Diez Tetamanti, 2014 y Diez Tetamanti y Rocha, 2016). En este camino paralelo entre práctica y construcción metodológica, aplicamos actualmente un dispositivo de trabajo que está diseñado con un esquema aproximado a lo siguiente: a) demanda local o iniciativa de investigación, que configura la idea inicial de trabajo; b) visitas y concurrencias aleatorias al lugar, donde suceden los encuentros de discusión sobre enfoques y objetivos de la propuesta; c) planificación de un derrotero para aplicar Cartografía Social, que implica una de las herramientas guía del proceso de mapeo y luego de sistematización; d) difusión del taller de Cartografía Social: esta difusión generalmente está a cargo de los referentes de la comunidad, como parte del proceso de apropiación de la actividad; e) evento de producción de las Cartografías Sociales: a partir de la formación de grupos y en el espacio consensuado por los referentes de la comunidad, que incluye un cierre con presentación de las cartografías y dinámica intertextual ${ }^{5}$ en términos de diálogo entre el grupo de trabajo y la comunidad, en la cual se intercambian abiertamente conclusiones parciales y observaciones sobre la experiencia de producción. Finalmente, y en algunas ocasiones, se produce un seguimiento de lo que podría ser un punto e) al cual denominamos inercia de intervención, donde la producción
3) Desde 2008 hasta la actualidad hemos ejecutado los siguientes proyectos relacionados con Cartografía Social: a) Inserción de la práctica de Cartografía Social en la Cátedra de Trabajo Social I de la UNLP, la cual se presenta como la primera experiencia de introducción de Cartografía Social en la Argentina (2008 y continúa) b) Cartografía Social en INTA Barrow, UNMDP, INTA, Fundación La Dulce (2008). c) Lo hice y lo aprendí, Carto- grafia Social para conocer el territorio (2011, SPU-PNVU. UNPSJB). d) Cartografía Social y SIG (2012-2013, SPUPVU. UNPSJB). e) Accesibilidad a la Salud Rural (2014-2016, SPU, PNVU y UTE, UNPSJB). En 2014 se creó la Cátedra Libre de Cartografía Social, a partir de la cual se dictaron cursos, talleres y servicios a organizaciones sociales y entes estatales como la provincia de Chubut, el INTA, ministerios, municipios y otras universidades nacionales e internacionales.

4) Nos referimos a intervención como la práctica de conocimiento, metodología, teoría y acción, puesta en función de procesos sociales existentes y su atención en problemáticas singulares (Carballeda, 2008). En este sentido, la extensión es parte indisociable de la intervención, en relación de la transferencia de conocimiento, metodología, teoría puestos en práctica fuera del ámbito académico.
5) En términos de Barthes, el concepto de intertexto es "lo que aporta a la teoría del texto el volumen de la socialidad: es todo el lenguaje, anterior y contemporáneo, que llega al texto no según la vía de una filiación identificable, de una imitación voluntaria, sino según la vía de diseminación (imagen que asegura al texto el estatuto no de una reproducción, sino de una productividad)" (1973:13). 
cartográfica cobra un nuevo significante, fuera del campo inicial (texto-mapa) donde se produjo la primer obra.

Los puntos indicados más arriba no son estrictos en su aplicación dado que existe una especial focalización en las posibles "derivas" que pueda tener el proceso de trabajo, por sobre el objetivo de mapeo social en sí. Al respecto resulta interesante resaltar dos instancias fundamentales que componen al dispositivo y que enmarcan a Cartografía Social como instancia de producción: la constitución y aplicación del derrotero y el evento de producción de las cartografías sociales.

El derrotero es "una secuencia de aspectos cartografiables y referenciables con un orden escénico que pueda ser sistematizado" (Diez Tetamanti y Rocha, 2016). Es una "referencialidad" que colabora como guía en la construcción del texto-mapa y con la posterior lectura de ese texto-mapa. El derrotero es el código simbólico que permitirá el diseño de la Cartografía Social a partir de aspectos en común. Al mismo tiempo, en el derrotero se explicita el objetivo del trabajo, los destinatarios y todo aquello que desee socializarse entre los cartógrafos sociales.

El derrotero constituye la guía para la tematización; discusión y producción del mapa social. Se trabaja con formato de "capas" que pueden ser diferenciadas con colores $u$ otras convenciones. Cada una de las capas puede incluir un subtema o elemento a cartografiar. Así, el derrotero es la guía en la "deriva" que proporciona el método cartográfico y que traza un rumbo (factible de ser modificado) por donde irá la discusión y la obra que producirá el mapa. Como parte integrante del dispositivo, es también factible de ser creado por la comunidad convocante al taller o los sujetos interesados en la elaboración de los mapas sociales. El armado del derrotero y la discusión en torno a sus implicancias es crucial, dada su relevancia en el "rumbo" del producto y las intencionalidades que éste pueda provocar al momento del evento de producción de las cartografías sociales. El evento de producción de las cartografías sociales es central en el dispositivo. La producción es siempre grupal, y en particular y a partir de la práctica, hemos optado el uso de hojas en blanco y trabajo en el suelo. La hoja en blanco amplía el vacío (ausencia) en función de la différance derridariana, que da cuenta de la ausencia de presencia — suprime la jerarquía entre ausencia y presencia y se instaura en un espacio que está más allá de la oposición entre los dos-, abre la posibilidad de todo sentido y de toda significación, muestra los límites y las condiciones de posibilidad de toda constitución de sentido (Narváez Cano, 2013). Así, la producción cartográfica se aleja del calco gráfico de la cartografía tradicional llustración 1

Esquema de derrotero propuesto para un "Taller de Cartografía Social Prospectiva" en la localidad de Astra. 2013

\section{Objetivo}

Piloto de un ejercicio de cartografía social, prospectivo para facilitar la coordinación con otros métodos de intervención y de investigación del territorio urbano.

\section{Para ello proponemos}

- Generar un mapa social del espacio urbano (sobre el futuro deseado) sobre un problema en particular sobre la base de los objetos, las relaciones, las prácticas y los conflictos.

- Construir un mapa social del espacio urbano (en el pasado) sobre un problema en particular sobre la base de los objetos, las relaciones, las prácticas y los conflictos. - Crear una identificación y explicación racional mapeada, acerca de los cómo lo procesos que permitieron el mapa futuro se lograron en realidad.

\begin{tabular}{|c|c|}
\hline \multicolumn{2}{|l|}{ Derrotero } \\
\hline ETAPA 1 & $\begin{array}{l}\text { Construcción del mapa (base) de [lugar]. } \\
\text { Vamos a incorporar en el mapa: } \\
\text { - Espacios públicos, calles, arroyos, cerros, plazas, etcétera. } \\
\text { - Edificios destacados (utilizados y abandonados; actuales y viejos). } \\
\text { - Instituciones (actuales y antiguas). } \\
\text { - Y todo aquello que consideremos deseable de incorporar. }\end{array}$ \\
\hline $\begin{array}{l}\text { ETAPA } 2 \\
\text { (color azul) }\end{array}$ & $\begin{array}{l}\text { FUTURO } \\
\text { Vamos cartografiar el [lugar] que deseamos. Para esto vamos } \\
\text { incorporar los objetos (nuevos y viejos); los conflictos, las prácticas } \\
\text { y las relaciones que esos objetos tienen con la sociedad. Tenemos } \\
\text { que considerar que esta Etapa } 2 \text { ya fue alcanzada. }\end{array}$ \\
\hline $\begin{array}{l}\text { ETAPA } 3 \\
\text { (color rojo) }\end{array}$ & $\begin{array}{l}\text { PASADO } \\
\text { Vamos a cartografiar el estado pasado del espacio a intervenir } \\
\text { (o sea, como es ahora, en el presente). Incorporamos objetos } \\
\text { existentes, conflictos actuales, prácticas sociales actuales y las } \\
\text { relaciones sociales. }\end{array}$ \\
\hline $\begin{array}{l}\text { ETAPA } 4 \\
\text { (color verde) }\end{array}$ & $\begin{array}{l}\text { Vamos a cartografiar (en el mismo mapa y la misma hoja), las } \\
\text { relaciones de objetos que tuvieron que suceder para alcanzar la } \\
\text { Etapa } 2 \text {. Después, vamos incorporar os conflictos emergentes, as } \\
\text { prácticas sociales que fueran tratadas y las relaciones que fueron } \\
\text { precisas de construir o romper para llegar a la Etapa } 2 \text {. } \\
\text { La Etapa } 4 \text { es la explicación racional de como pasamos de la Etapa } \\
3 \text { a la Etapa } 2 \text {. }\end{array}$ \\
\hline ETAPA 5 & al del proceso. \\
\hline
\end{tabular}

Fuente: elaboración propia

e invita a producir una nueva proyección consensuada y elaborada a partir de una intertextualidad cartográfica con identidad en el grupo de cartógrafos sociales. $Y$ volvemos a la idea de un evento diegético, tal como mencionamos antes. Lo que sucede con la hoja en blanco, como doble función mimética-diegética es una dinámica pendular entre el calco, característico de la mímesis, y la producción 
de un espacio singular que sólo es factible a partir de la subjetividad individual de cada cartógrafo social, colectivizada en la producción del dibujo cartográfico. Así es que el proceso deconstructivo interviene, a partir del cuestionamiento de la propia presentación tradicional cartográfica, en tanto escala, precisión, fiabilidad, representación gráfica, símbolos, formas. Los cartógrafos sociales crearán nuevos modos de presentación, simbología, forma, escala, poniendo en cuestión los modos conocidos, para abrir el camino a la textura de la escala social.

El trabajo en el suelo proporciona horizontalidad a la vez que provoca una nueva sensación de innovación en el uso del espacio de trabajo. Esta situación invita a los cartógrafos sociales a ocupar un espacio nuevo que frecuentemente no utilizan o no experimentan desde la niñez, al tiempo que horizontaliza las diferencias, la acción y pone al desnudo el uso de todo el cuerpo en el proceso cartográfico.

El evento de producción de las Cartografías Sociales, implica además registros diversos que no solo se focalizarán en el mapeo y su grafía. Otros elementos conforman parte de la escena. Son registrados tanto por los propios cartógrafos sociales como por el grupo de trabajo organizador. Así, la dinámica de grupo (en tanto relaciones de poder, permisos, ausencias, directivas y omisiones), las posturas corporales (con relación a los vínculos grupales, incomodidad, comodidades, expresividad no verbal) (Knapp, 1992) y la presentación de las cartografías y dinámica intertextual como instancia final del evento, la cual transforma al mapeo en texto-presente como presencia plena del sentido que el grupo otorgó al mapeo a partir de la oralidad. En síntesis, esta instancia de presentación de las cartografías es el momento en el que con el intercambio y el diálogo, tanto dentro del grupo como hacia afuera y con los otros, cobra el sentido de texto completándose como producto.

Cada taller de Cartografía Social llevado adelante nos presenta nuevas formas de experimentar el espacio, recorrerlo y producirlo. Nos encontramos con otros territorios a partir del diálogo entre las "diferencias" en comunión productiva. Cuestiones que siempre responden a lo subjetivo y lo cognitivo y que el punto de vista de la cartografía dominante se encargó de expulsar (Segura, 2010). En las experiencias de Cartografía Social llevadas a cabo dentro del grupo de trabajo el mapeo social tiende a ser un ejercicio y recorrido trabajado a lo largo y ancho de diferentes escalas espaciales: rurales, urbanas, ciudades y pequeñas localidades. Dado que en la construcción del mapa social confluyen múltiples textos subjetivos sobre un mismo territorio o lugar, no se concibe ni se produce una sola ciudad, sino múltiples ciudades, múltiples barrios, múltiples lugares que convergen luego de un proceso de interacción, negociación y discusión. En este sentido, se concibe a la ciudad, tal como plantea Lindón (2007), como un mosaico de lugares que han sido y son construidos socialmente en un proceso siempre inconcluso. Allí la práctica de Cartografía Social ingresa en la visibilización y reflexión sobre los imaginarios sociales, es decir sobre aquellos significados y sentidos reconocidos socialmente que otorgan cualidad a los lugares y que se constituyen dentro de contextos y procesos históricos.

Un mismo lugar de la ciudad, un mismo barrio, adquiere diferentes significados de acuerdo con la conjunción de múltiples sentidos y textos que prosperan en el proceso de Cartografía Social. Un "pasaje" con escaleras en el barrio San Martín de Comodoro Rivadavia es cartografiado en el mapa social de los chicos de sexto grado como un lugar desagradable por su aspecto físico y hechos delictivos asociados; mientras que para el grupo de adultos mayores ese mismo espacio se reconstruye a través de la memoria ${ }^{6}$ como un lugar agradable donde se puede transitar en cualquier momento del día. ${ }^{7}$ Podemos encontrar diversos ejemplos sobre los diferentes significados que adquiere un lugar a partir de las experiencias que intercambian los sujetos. Un parque o una plaza pueden ser experimentados en doble función temporal, como lugar agradable durante el día mientras que de noche se torna un lugar peligroso "principalmente porque hay gente que va a tomar ahí" (alumno de sexto grado).

A través de Lindón (2007), podemos pensar al mapa social como un holograma espacial donde emergen imaginarios urbanos que cuentan sobre diversos planos de la realidad. Incluso evidencian elementos ausentes pero presentes en la memoria e imaginarios espaciales de los sujetos. Estos hologramas espaciales se proponen como escenarios situados en un lugar y tiempo concretos, con la peculiaridad de que en este lugar están presentes otros lugares que actúan como constituyentes de este lugar o escenario, conformando una red de lugares interconectados a través de lo experimentado. Es así que en este escenario confluyen las experiencias espaciales vividas de otros lugares y que construyen al lugar en que se sitúa el escenario, a través de narrativas espaciales que tienen un protagonismo enriquecedor y que se corporizan de manera colectiva en la producción cartográfico, principalmente, a través del reconocimiento de un otro como igual, interrogando(nos) sobre nociones y estigmas de personas, límites y lugares, preestablecidos y representados como peligrosos, nocivos y desagradables.

El mapa se traduce como instrumento de saber-poder. Al limitar y omitir, las personas expresan y son parte de un discurso. Considerando esta noción, asociado a otro ejercicio de Cartografía
6) Sobre mapas de la memoria, véase Diez Tetamanti, 2014.

7) Ejercicio de Cartografía Social llevado a cabo en el mes de mayo de 2016 en la Escuela № 184 Juan Domingo Perón del barrio San Martín de la ciudad de Comodoro Rivadavia, en el marco de la ejecución del Proyecto de Extensión Universitaria, denominado
"Construcción social comunitaria del espacio público en barrios de Comodoro Rivadavia-Chubut" (SPU-UNPSJB). 
Social en Comodoro Rivadavia con vecinos, dirigentes vecinales y demás participantes provenientes de diferentes instituciones, la delimitación se hizo explícita en cada mapa social, principalmente en el reconocimiento de los barrios y sus límites. Las líneas divisorias entre los barrios "San Cayetano" y "Máximo Abasolo", por ejemplo, atravesaron cada cartografía realizada por los cartógrafos sociales. En este devenir estricto de representar los límites del barrio en el mapa también se hicieron presentes aquellos límites móviles y desconocidos dentro del propio barrio. Los criterios de delimitación fueron variando, pero su perspectiva más general apuntó a aquellas zonas que se identificaban ajenas al territorio o al barrio por encontrarse en límites difusos o porque las dividía "una línea muy fina donde nadie se hace cargo, pero todos conocemos" (vecina). En este sentido, las representaciones en el mapa hacían alusión a los márgenes o periferia como "fuera del barrio", donde a su vez se ubicaban los asentamientos informales, asociándolos como los lugares donde "falta de todo" y son el "foco infeccioso". ${ }^{8}$ En las experiencias grupales con Cartografía Social, los procesos de identificación y constitución de identidades se evidencian en el producto mapa social a través de marcas y grafías pero por sobre todo en el gran texto que emerge de la intertextualidad. Es decir, el mapa social en el papel no es el producto final porque es sólo un objeto de ausencia. El mapa siempre es acompañado de una explicación y un argumento que en ese todo, es texto y es presencia emergente de diálogo.

Sobre la base de los procesos anteriormente ejemplificados, planteamos al mapa social como un escenario de encuentros, desencuentros y conflictos sobre diferentes formas de habitar un mismo lugar. Esto (nos) lleva a la interpelación como vecinos, movilizando otros sentidos sobre, por ejemplo, mi propio barrio, una calle o un "pasaje", como el caso del barrio San Martín. Con relación a esto, también se crean formas de empoderamiento y vinculación en un plano horizontal (mapa-texto) que permiten proyectarse, en muchos casos, a propuestas de intervención territorial. Y cabe destacar, en el taller de Cartografía Social en el barrio San Cayetano, el intercambio de información donde los participantes desconocían cuestiones sobre su propio barrio con referencia a campañas que lleva adelante el Centro de Salud sobre saneamiento ambiental y que a partir del proceso de intercambio socializaron.

La cartografía sale de este modo del mapa para situarse en todo el texto que presenta el territorio. Encontramos aquí una manera de saltar algunos de los límites que impone la metodología tradicional para ingresar al compromiso y construcción del territorio analizado desde la población que habita el lugar.

Podemos decir que los vínculos y procesos de empoderamiento ciudadano que surgen a través de la Cartografía Social encontraron manifestación, por ejemplo, en la localidad de Aldea Beleiro, ${ }^{9}$ cuando al trabajar la problemática de acceso a la salud en el área a partir de la falta de profesionales médicos y otros recursos se obtuvieron como parte de los resultados: textos, mapas y debate, que sirvieron para la implementación de solicitudes ante diferentes estamentos de la administración pública y de salud. Esto contribuyó a que algunos habitantes de la localidad se reunieran para enviar una carta dirigida a la gobernación, solicitando la presencia de un médico permanente. Esta acción-intervención surgió de manera voluntaria por los propios habitantes, movilizados por las discusiones en torno al mapeo social, principalmente en el reconocimiento de su situación local con respecto a la salud y las necesidades implicadas.

\section{Reflexiones finales}

Entre los avances de este proceso iniciado en el camino de la Cartografía Social se concentra la de intercambio para crear cartografías diferentes, pensándolo como un acto de resistencia motorizado por la libertad de poder construir territorios deseados, queridos e imaginados de manera colectiva. En este sentido, consideramos el acto más significativo de este proceso metodológico que es, el de otorgar "el lápiz al pueblo".
8) Taller de Cartografía Social realizado en barrio San Cayetano de la ciudad de Comodoro Rivadavia, en noviembre 2014, a partir de la demanda de equipo técnico de la Dirección de Hábitat de la Municipalidad de Comodoro Rivadavia, en el marco de la ejecución del Programa de Mejoramiento Barrial. 9) Se llevo a cabo en el año 2013 un taller de Cartografía Social en la loca- lidad de Aldea Beleiro en la provincia de Chubut, a través de la ejecución del Voluntariado Universitario "Cartografía Social, jugando otra vez para conocer nuestro territorio" (2012-2013) y el
Proyecto de Investigación "Cartografía Social, investigación e intervención desde la geografía" (PI 044. UNPSJB. 2012-2014). 
Nos moviliza pensar que cada experiencia con Cartografía Social genera instancias de encuentros y desencuentros que tienen como elemento fundamental la reflexión sobre lo común a partir de la experiencia sobre el espacio que vivimos. La posibilidad de producir un mapa, incluido dibujo y texto, deconstruyendo convenciones estrictas a las que tan domesticados estamos. Los fines de generar un producto común como parte de la práctica cartográfica no sólo suponen la construcción, en plano horizontal, de un mapa-texto, sino también la implicación de los sujetos como partícipes de la investigación-extensión-intervención en carácter crítico y reflexivo sobre sus propias prácticas.

La continuidad en la práctica de extensión como parte de la construcción metodológica, genera una apertura que va más allá de los textos académicos para adentrarnos en las texturas sociales que implican otros ritmos, otras definiciones y, particularmente, otros temas. Estos otros temas ingresan cómodamente a partir del proceso cartográfico social, ya que en la propia producción de mapeos hay también una doble producción: de conocimiento y de problematización de la realidad.

En este sentido, y ante la complejización metodológica y epistemológica en la que va incursionando la práctica de Cartografía Social, se hace necesario pensar en profundizar su curricularización. Entendemos que, a medida que la bibliografía del tema vaya generado nuevos aportes, esto será más interesante aún. No obstante, el camino recorrido con Cartografía Social nos demuestra permanentemente cómo una práctica adquiere ingredientes metodológicos que colaboran en posibles modos de sistematizar, así como sucedió con la deriva de Debord o el método cartográfico de Deleuze, los cuales actualmente son ampliamente aplicados en las facultades brasileñas de arquitectura, geografía, psicología, arte y diseño; entre otras. En este marco, la curricularización se enfrenta a un interesante desafío, amojonado principalmente por las estructuras más conservadoras de la academia, que solicitan fundadas pruebas de que cada método es eficaz y que posee suficientes antecedentes teóricos, para permitirle así formar parte del selecto grupo de "elementos" que juegan dentro de las paredes universitarias. Por esto, desde nuestro grupo de trabajo nos planteamos la motivadora tarea de crear la Cátedra Libre de Cartografía Social, la cual consideramos solo un paso más en la curricularización, que en parte de este proceso de creación en la Universidad Nacional de la Patagonia San Juan Bosco, algunas cátedras ya lo incluyen en sus programas de estudio. ${ }^{10}$ Desde la Cátedra Libre se presenta una puerta a la curricularización que va de la mano de la innovación y la osada tarea de aprender a errar. La extensión, en su a veces estigmatizado camino metodológico, cuenta también con este tipo de herramientas que permiten ingresar al seno de la currícula universitaria, saliendo e ingresando permanentemente, generando un diálogo esquizofrénico, en términos deleuzianos, que habilita a generar pruebas tanto desde la extensión como desde la intervención, la docencia y la investigación. La tarea de profundizar en Cartografía Social está iniciada y va de la mano de aquellos otros intentos de llevar la práctica aprehendida a sus sistematizaciones metodológicas, lo que no es otra cosa que un modo genuino de experimentar en ciencias sociales.

Finalmente, creemos que desde la Cartografía Social es posible abrir un nuevo espacio de acción para la Geografía, tanto desde la comunión entre sujeto y objeto como desde la perspectiva de construcción de argumentos sobre el espacio geográfico. Una construcción de argumentos de mayor armonía con los procesos sociales que acontecen fuera del corpus académico y el enfoque más analítico, tan distanciado de la textura social, mediante datos, indicadores y esquemas racionales.

La Geografía tiene nuevas intertextualidades para aportar a la discusión sobre lo social. Aportes que implican una presencia permanente en el diálogo entre experiencia, deconstrucción y producción, creando así espacios que nos permitan pensar en otros modos de desear, proyectar y construir el territorio que vivimos colectivamente.
10) Las cátedras que al momento de realizar este artículo incluyen Cartografía Social en sus programas de estudio son: Ordenamiento Territorial, Metodología de la Investigación Geográfica, Cartografía y Trabajo Social IV. 


\section{Referencias bibliográficas}

Agamben, G. (2011). ¿Qué es un dispositivo? Sociológica, 26 (73), 249-264. Barthes, R. (1973). Teoría del Texto. Traducido y tomado de la Enciclopedia de la Pléyade, p. 13. (versión original francesa 1973, tomo XV de la Encyclopedia Universalis).

Burch, N. (1987). El tragaluz del infinito. Madrid: Cátedra.

Carballeda, A. (2008). La Intervención en Lo Social, las problemáticas sociales complejas y las políticas sociales. Margen, (48) (online): http://www.margen.org/ suscri/margen48/carbal.html (consulta, marzo de 2010).

Careri, F. (2014). Walkscapes ten years after. Revista de Estudios Urbanos y Ciencias Sociales, 4 (1), 207-213. http://www2.ual.es/urbs/index.php/urbs/article/ view/careri

Debord, G. (1999 [1958]). Teoría de la deriva. Internationale Situationniste. Traducción extraída de Internacional Situacionista, I: La realización del arte. Madrid: Literatura Gris.

Debord, G. y Wolman, G.J. (1956). Métodos de tergiversación. Les Levres Nues, 8. Traducción extraída de la página web www.sindominio.net/ash/presit02.htm Deleuze, G. (2007). ¿Qué es un dispositivo? En Foucault, M. filósofo, 1990. BarceIona: Gedisa.

Deleuze, G. (2009). Lógica do Sentido. São Paulo: Editora 34.

Deleuze, G. y Guattari, F. (1995). Mil platôs: capitalismo e esquizofrenia. Vol. 1. São Paulo: Editora 34.

Deleuze, G. y Guattari, F. (1998). El Anti-Edipo. Capitalismo y esquizofrenia. Trad. a cargo de Francisco Monge. Barcelona: Paidós. 2da. Edición. Versión en francés fd L'Anti-Oedipe. Capitalisme et schizophrénie. Paris: Les Éditions de Minuit, 1972. Diez Tetamanti, J.M. (2014). Hacia una Geografía Comunitaria. Buenos Aires: Ed. Universitaria de la Patagonia.

Diez Tetamanti, J.M. y Rocha, E (2016). Cartografía Social aplicada a la intervención social en el barrio Dunas, Pelotas, Brasil. Geográfica de América Central, 2

(58). Universidad de Heredia Costa Rica.

Diez Tetamanti, J.M. y Escudero, B. (2012). La construcción de un dispositivo de intervención a través de Cartografía Social. En Diez Tetamanti, J.M. y otros, Cartografía Social: investigación e intervención desde las ciencias sociales, métodos y experiencias de aplicación. Buenos Aires: Ed. Universitaria de la Patagonia.

Foucault, M. (1979). Microfísica del poder. Madrid: La Piqueta.

Foucault, M. (2001). Ditos e escritos. Forense Universitária, III. Rio de Janeiro. García Barón, C. (2007). Barrios del mundo: historias urbanas la cartografía social... pistas para seguir. Online en: http://ccra.mitotedigital.org/node/362 Hall, S. (2003). Introducción: ¿quién necesita "identidad"? (13-38). En Hall, S. y Du Gay, P. (Comps.), Cuestiones de identidad cultural. Buenos Aires: Amorrortu.
Kastrup, V. (2014). Cartografiar é traçar um plano común. Pistas do método da cartografia, 15-41. Porto Alegre: Sulina.

Knapp, M. (1992). La comunicación no verbal, el cuerpo y el entorno. Barcelona: Paidós.

Lindón, A. (2007). Los imaginarios urbanos y el constructivismo geográfico: los hologramas espaciales. Eure, XXXIII (99), 31-46. Pontifica Universidad Católica de Chile.

Lois, C. (2009). Imagen cartográfica e imaginarios geográficos. Los lugares y las formas de los mapas en nuestra cultura visual. Scripta Nova. Revista Electrónica de Geografía y Ciencias Sociales, XIII (298). Barcelona: Universidad de Barcelona. Online en: http://www.ub.es/geocrit/sn/sn-298.htm

Lynch, K. (1986). La imagen de la ciudad. Buenos Aires: Infinito. (Original: The Image of the City. Boston, MIT Press, 1960).

Mattos, J.; Damas, M. y Cavalli, T. (2014). Cartografias Participativas como Metodologia de Aproximação a Conflitos Territoriais: relatos sobre o elo entre teoria e realidade dentro das práticas de extensão. Anais VII Congreso Brasileiro de Geógrafos. Vitoria, Brasil.

Montoya, V. (2007). El mapa de lo invisible. Silencios y gramática del poder en la cartografía. En Revista Universitas Humanística, 063, 155-179. Pontificia Universidad Javeriana. Bogotá.

Narváez Cano, P. (2013). Derrida y algunas implicaciones ético-políticas de la deconstrucción de la presencia. Documento Ceso 204. Universidad de los Andes. Bogotá.

Norris, C. (1987). Derrida en Cambridge, Harvard University Press.

Passos, E.; Kastrup, V. y Escóssia, L. (2009). Pistas do método da cartografia: Pesquisa-intervenção e produção de subjetividade. Porto Alegre: Sulina.

Piza Cubides, J. (2009). La cartografía social como instrumento metodológico en los procesos de construcción de territorio a partir de la participación ciudadana en la planeación territorial y la construcción del espacio público. Tesis de Maestría en Planeación Urbana y Regional. Pontificia Universidad Javieriana. Bogotá.

Segura, R. (2010). Cartografías discrepantes. Análisis de las representaciones socioespaciales de la ciudad. Periferia. Universidad Estadual de Río de Janeiro, UERJ Río de Janeiro.

Torres Ribeiro, A. (2009). Cartografia da ação social. Região latino-americana e novo desenvolvimento urbano. Poggiese, H. y Cohen Egler, T.T. (Comps.), Otro desarrollo urbano: ciudad incluyente, justicia social y gestión democrática.1a edición. Buenos Aires: Consejo Latinoamericano de Ciencias Sociales-CLACSO. Vara Muñóz, J. (2010). Un análisis necesario: epistemología de la geografía de la percepción. Papeles de Geografía, (51-52), 337-344. 